Published in final edited form as:

J Pain. 2013 September ; 14(9): 983-996. doi:10.1016/j.jpain.2013.03.011.

\title{
Multisystem Dysregulation in Painful Temporomandibular Disorders
}

\author{
Hong Chen ${ }^{*}, \dagger, \ddagger$, Andrea Nackley ${ }^{*}, \ddagger$, Vanessa Miller ${ }^{*}$, Luda Diatchenko* ${ }^{*}$, , and William \\ Maixner ${ }^{*} \neq$ \\ *Regional Center for Neurosensory Disorders, University of North Carolina-Chapel Hill, School of \\ Dentistry, Chapel Hill, North Carolina \\ tOral and Maxillofacial Pain Clinic, University of North Carolina-Chapel Hill, School of Dentistry, \\ Chapel Hill, North Carolina \\ ‡Department of Endodontics, University of North Carolina-Chapel Hill, School of Dentistry, \\ Chapel Hill, North Carolina
}

\section{Abstract}

Multiple physiological and psychological regulatory domains may contribute to the pathophysiology of pain in temporomandibular disorder (TMD) and other bodily pain conditions. The purpose of this study was to evaluate the relationship between multisystem dysregulation and the presence of TMD pain, as well as the presence of different numbers of comorbid pain conditions in TMD. Secondary data analysis was conducted in 131 non-TMD (without comorbid pain) controls, 14 TMD subjects without comorbid pain, 78 TMD subjects with 1 comorbid pain, and 67 TMD subjects with multiple comorbid pain conditions who participated in a TMD genetic study. Twenty markers from sensory, autonomic, inflammatory, and psychological domains were evaluated. The results revealed that 1 ) overall dysregulation in multiple system domains (OR [odds ratio $]=1.6,95 \%$ confidence interval $[\mathrm{CI}]=1.4-1.8)$, particularly in the sensory $(\mathrm{OR}=1.9$, $95 \% \mathrm{CI}=1.3-2.9)$ and the psychological $(\mathrm{OR}=2.1,95 \% \mathrm{CI}=2.1-2.7)$ domains, were associated with increased likelihood of being a painful TMD case; and 2) dysregulations in individual system domains were selectively associated with the increased odds of being a TMD case with different levels of comorbid persistent pain conditions. These outcomes indicate that heterogeneous multisystem dysregulations may exist in painful TMD subgroups, and multidimensional physiological and psychological assessments can provide important information regarding pathophysiology, diagnosis, and management of pain in TMD patients.

Perspective-The concurrent assessment of multiple physiological and psychological systems is critical to our understanding of the pathophysiological processes that contribute to painful TMD and associated comorbid conditions, which will ultimately guide and inform appropriate treatment strategies that address the multisystem dysregulation associated with complex and common persistent pain conditions.

(C) 2013 by the American Pain Society

Address reprint requests to Hong Chen, DDS, MS, Regional Center for Neurosensory Disorders, School of Dentistry, University of North Carolina-Chapel Hill, CB \#7450, Chapel Hill, NC 27599. hongchen@unc.edu.

Drs Maixner and Diatchenko are equity shareholders in and consultants to Algynomics. The rest of the authors disclose no conflict of interest.

Supplementary data accompanying this article are available online at www.jpain.org and www.sciencedirect.com.

Supplementary Data

Supplementary data related to this article can be found at http://dx.doi.org/10.1016/j.jpain.2013.03.011. 


\section{Keywords}

Temporomandibular disorders; multisystem dysregulation; comorbid pain conditions; headache

Painful temporomandibular disorders (TMDs) are a heterogeneous group of conditions that affect $5 \%$ of the adult population. ${ }^{30}$ In addition to facial pain, concomitant bodily pain conditions are reported by approximately $60 \%$ of individuals with painful TMD. ${ }^{52,53,77}$ Recent studies suggest different pathophysiologies in TMD subgroups with localized versus generalized bodily pain profiles. ${ }^{52,68}$ Generalized bodily pain has also been associated with the persistence of TMD symptoms ${ }^{55,57,80}$ and poor treatment outcome. ${ }^{33,58}$ Therefore, the relationship between bodily pain profiles and the underlying pathophysiology for TMD pain warrants further exploration to better inform mechanism-based diagnosis and treatment in TMD.

Extensive literature suggests that multiple regulatory domains associated with sensory, autonomic, inflammatory, and psychological function may all contribute to the pathophysiology of pain in TMD and other bodily pain conditions. ${ }^{13,24,35,54,56,59,66,85,89}$ These regulatory domains are interconnected and are integrated by the central nervous system (CNS) to maintain homeostasis. ${ }^{11,14}$ Pain experience can therefore be modulated through different pathways within this integrated CNS regulatory network. ${ }^{11}$ Because of the interconnectivity between different regulatory domains and the parallel multisystem modulation within the CNS, multiple compensatory systems contribute to pain processing and modulation. Therefore, an assessment of the function of multiple regulatory systems should be assessed when evaluating the diverse heterogeneous processes that contribute to the experience of chronic pain.

Consistent with the biopsychosocial model for chronic pain, ${ }^{19}$ multidimensional physical and psychosocial measures are required to understand the etiologic factors and mechanisms that underlie chronic TMD. ${ }^{1,18,62}$ However, current assessment and diagnosis of TMD is primarily based on signs and symptoms associated with the orofacial region, which fails to integrate the contributions from other system domains, resulting in an incomplete understanding of the pathophysiological mechanisms that contribute to painful TMD conditions.

The aims of this study are to evaluate regulatory systems that are associated with painful TMD, as well as with TMD subgroups that express different numbers of comorbid bodily pain conditions. We hypothesize that compared to controls, 1) the sum measure of multisystem dysregulation is associated with the odds for painful TMD case status, as well as for TMD subgroup status, which is based on the number of comorbid pain/sensory conditions; and 2) individual domain measures of dysregulation are associated with the odds for painful TMD case status, as well as for TMD subgroup status based on the number of comorbid pain conditions. In this study, clinical pain profiles were also detailed for TMD subgroups. Part of this work was presented at the 2012 annual scientific meeting of the American Academy of Orofacial Pain.

\section{Methods}

\section{Study Participants and Classification}

This study is a secondary analysis using existing data from a case-control study investigating genetic risk factors for TMD (R01 DE 16558, L.D. and W.M.). Among all 349 participants in whom comorbid pain and multisystem regulation were measured, 290 subjects fulfilled the inclusion/exclusion criteria and were included in this study. Data were collected between 
2005 and 2009. Female volunteers were recruited from the Orofacial Pain Clinic at the University of North Carolina at Chapel Hill, NC, as well as from the university campus and community by advertisements, flyers, and mass email. Participation was limited to white women because of the higher prevalence of TMD in women than in men, and to avoid problems of population stratification in assessing genetic associations. Participants were aged 18 to 60 years old. Exclusion criteria included the following self-reported medical conditions: diabetes, kidney disease, heart failure, chronic respiratory disease, epilepsy or seizure disorder, or high blood pressure not controlled with medication. Women who were pregnant, nursing, undergoing orthodontic treatment, dialysis, radiation, or chemotherapy were similarly excluded from participation, as were participants with trauma or surgery on the head, face, or neck within the past 6 months. This study was approved by the Biomedical Institutional Review Board of the University of North Carolina at Chapel Hill. Written informed consent was obtained from all study participants.

TMD Case Classification-Case classification of TMD was based on the following criteria: 1) a self-reported history of pain in the temporomandibular region for at least 5 days in the month preceding the clinical examination and 2) the presence of myalgia and/or arthralgia of TMD based on a modified version of the Research Diagnostic Criteria for Temporomandibular Disorders (RDC/TMD; see Chen et al ${ }^{12}$ for detailed descriptions). This RDC/TMD clinical examination was performed by calibrated examiners on all subjects to determine TMD case or noncase status.

Classification of Comorbid Pain Conditions-The presence of 7 persistent pain conditions, namely, fibromyalgia, chronic fatigue syndrome (CFS), irritable bowel syndrome (IBS), interstitial cystitis, chronic pelvic pain, frequent headaches, and frequent low back pain, were examined by self-report (see Clinical Pain Measures section). TMD cases were further arbitrarily classified into 3 subgroups based on the number of comorbid pain conditions: 1) TMD only (without comorbid pain); 2) TMD + 1 pain (with 1 comorbid pain condition); and 3) TMD $+\geq 2$ pain (with multiple, ie, 2 or more, comorbid pain conditions).

Control subjects reported no history of orofacial pain within the preceding 6 months and no prior diagnosis of TMD. In addition, the RDC/TMD clinical examination determined the absence of arthralgia and myalgia. Controls were also of absence of persistent comorbid pain conditions.

\section{Clinical Pain Measures}

Self-reported questionnaires were used to assess the severity and impact of facial pain and other bodily pain in TMD and control participants.

Comprehensive Pain Symptom Questionnaire-The Comprehensive Pain Symptom Questionnaire is a self-report instrument assessing presence of multiple pain symptoms and their associated characteristics. The presence of the comorbid persistent pain conditions (ie, fibromyalgia, CFS, IBS, interstitial cystitis, and chronic pelvic pain) were determined by the following question: "Do you have any of the following conditions or symptoms?" The presence of frequent headache(s) was determined by headaches that have been present for at least 3 months or at least 10 episodes in the last year, and on an average of 1 or more headache day per month. The presence of frequent low back pain was determined by a positive history and at least 11 episodes of low back pain in the past 12 months. These frequency criteria were arbitrarily selected to represent persistency of pain based on available data. Psychometric properties of the instrument have been assessed for items such as presence of jaw pain (in past 30 days and lifetime), headache in the past year, and jaw 
pain frequency. The validity coefficients range .85 to 1.0 versus expert interview, and temporal stability ranges .7 to .9 over 3 to 7 days (R. Ohrbach et al, 2011, unpublished data).

Graded Chronic Pain Scale-The Graded Chronic Pain Scale (GCPS) includes 6 items that rate the intensity of current pain as well as intensity and pain interference with activities in the past 6 months. All items are rated from 0 to 10 . The derived pain severity score is graded into 4 hierarchical classes: Grade I, low disability-low intensity; Grade II, low disability-high intensity; Grade III, high disability-moderately limiting; and Grade IV, high disability-severely limiting. GCPS has been validated in primary care and chronic pain patients. ${ }^{81}$ In the present study, Grade I and Grades II to IV were dichotomized to represent the absence (Grade I) or presence (Grades II-IV) of "clinical significant pain," as persons with Grades II to IV commonly present with intense pain and/or pain-related dysfunctions. ${ }^{80}$ We assessed GCPS rating for both facial pain and "other pain" (ie, bodily pain other than facial pain).

Screening Pain Self-Report-The Screening Pain Self-Report is a 5-item questionnaire that rates the recent pain intensity (ie, average, highest, and lowest; range 0-100), average percentage of waking day during which individuals experience pain, and a rating of current pain corresponding to descriptive words that represent the sensory (intensity) and affective (unpleasantness) domains of the pain experience. ${ }^{23}$

\section{Multisystem Regulation Measures}

Based on evidence of system contributions to pain amplification and on availability of data being collected, we selected 4 domains to investigate the association of impairments in multiple domains with TMD and TMD with common comorbidities. These domains were sensory, autonomic, inflammatory, and psychological domains, which are domains that appear to differ between chronic TMD cases and non-TMD cases. ${ }^{20,25,39,40,68}$

Sensory Domain Measures-Sensory responses to pressure pain and heat pain stimuli were selected as they have been associated with TMD cases. ${ }^{25,52}$ As detailed below, multiple measures were selected to examine different components of sensory processing and regulation. ${ }^{25}$

Pressure Pain Sensitivity: Pressure pain threshold (PPT) at lateral epicondyle and widespread palpation tenderness (WPT) were assessed to reflect generalized pressure pain sensitivity. ${ }^{12}$ The PPT was measured using a flat-tipped algometer (Pain Diagnosis and Treatment, Great Neck, NY) applied to lateral epicondyle. Pressure was applied at a steady rate of $1 \mathrm{~kg} / \mathrm{second}$ until the participant indicated that she felt pain. After an initial test trial, 2 subsequent and consecutive readings that differed by no more than $.2 \mathrm{~kg}$ were averaged and recorded as the PPT. Two reproducible readings were generally obtained within 3 trials after the initial test trial. WPT was determined by digital palpation examination at 18 predefined bodily sites modeled after the American College of Rheumatology's 1990 criteria $^{86}$ for fibromyalgia tender points examination: occiput, trapezius, supraspinatus, lower cervical, second rib, lateral epicondyle, knee, gluteal, and greater trochanter. Three pounds of digital palpation pressure were applied bilaterally for 2 seconds to each site. At each location, a response of pain to palpation was recorded as "tenderness." WPT was classified as present when palpation tenderness was elicited bilaterally and above and below the waist, that is, at least in diagonal locations.

Heat Pain Sensitivity: Heat pain tolerance, temporal summation, and a single (first) heat pain rating were selected for heat pain sensitivity. These measures were assessed using a commercially available thermal stimulator (Medoc Ltd, Ramat Yishai, Israel). This device 
delivered computer-controlled slowly increasing thermal stimuli to the skin on the left medial ventral forearm at a rate of $.5^{\circ} \mathrm{C} / \mathrm{second}$ from an adapting temperature of $39^{\circ} \mathrm{C}$. The subject terminated the stimuli by pressing a button when it became intolerable (thermal pain tolerance). Thermal pain tolerance was defined as the highest temperature that could be tolerated (with an upper limit of $50^{\circ} \mathrm{C}$ ). Four sites were tested for tolerance, with each site being at least 1.5 inches apart. Four trials of tolerance were conducted to obtain an average temperature value.

Following heat pain tolerance testing, participants judged the pain intensity evoked by suprathreshold heat stimuli, verbally reporting on a numerical rating scale (NRS) between 0 and 100, where 0 represented no pain and 100 represented the most intense pain imaginable. Participants were told that they would receive 10 thermal stimuli in a row and would be verbally cued to report their peak pain intensity after each stimulus. For more detailed description of the protocol, see Greenspan et al. ${ }^{25}$ NRS responses to repeated thermal stimuli were plotted against time to derive the summary measure of temporal summation for each subject as the slope of a linear regression line fitted for the first 5 NRS responses. Also, the subject's first NRS was used as a measure of initial thermal sensitivity.

Autonomic Domain Measures-Resting blood pressure (BP, systolic [SBP], diastolic [DBP]) and heart rate (HR) were selected because of data availability and because elevations in these measures have been observed in TMD and associated pain conditions and have been related with central pain dysregulation. ${ }^{4-6,34,40,61,89} \mathrm{BP}$ and $\mathrm{HR}$ were measured in a seated position after a rest period of 3 to 5 minutes, using an autonomic monitor (Dinamap; GE Healthcare, Milwaukee, WI). A pneumatic cuff was positioned around the right arm. Three readings were taken 2 minutes apart and were averaged for BP and HR measures. Rate pressure product $(\mathrm{RPP}=\mathrm{HR} \times \mathrm{SBP}$ ) was also evaluated to reflect the autonomic nervous system function. The hemodynamic components of RPP are modulated by both sympathetic and parasympathetic branches of the autonomic nervous system. RPP has been used in cardiology as an indicator of cardiac workload ${ }^{9}$ and myocardial oxygen consumption. ${ }^{21}$

Inflammatory Domain Measures-Circulating cytokines were selected because of their association with increased pain in TMD and related pain conditions. ${ }^{3,27,28,78,83}$ Cytokines are small intracellular regulatory proteins secreted by immune cells that contribute to the pathophysiology of TMD and related comorbid conditions. Elevated levels of proinflammatory cytokines (eg, interleukin-1 [IL-1] and interleukin-8 [IL-8]) have been found locally in temporomandibular joint fluid ${ }^{29,42,48,74}$ and systemically in circulating blood of patients with TMD. ${ }^{47,68}$ Additionally, elevated proinflammatory cytokine levels have been correlated with greater pain sensitivity, $, 1,48,65,74$ perceived stress, ${ }^{37}$ and depressed mood, ${ }^{38}$ which are phenotypes characteristic of TMD and related pain conditions. Abnormalities in levels of proinflammatory cytokines are often accompanied by alterations in levels of anti-inflammatory cytokines (eg, IL-1 receptor antagonist [IL-1ra]), 2,32,46,68,75 associated with reductions in pain and inflammation. $32,49,84$

For the purpose of this study, we chose to analyze a subset of 11 cytokines from the study data set that had reliable measures (for specific details pertaining to measurement of cytokines, please refer to Slade et $\mathrm{al}^{68}$ ). This subset included the following proinflammatory cytokines: epithelial-derived neutrophil-activating peptide 78 (ENA-78), fibroblast growth factor basic (FGF basic), granulocyte colony stimulating factor (G-CSF), interleukin-6 (IL-6), interleukin-8 (IL-8), macrophage inflammatory protein-1 $\beta$ (MIP-1 $\beta$ ), monocyte chemotactic protein-1 (MCP-1), thrombopoietin (Tpo), tumor necrosis factor- $\alpha$ (TNF- $\alpha$ ), vascular endothelial growth factor (VEGF), and the anti-inflammatory cytokine interleukin-1 receptor antagonist (IL-1ra). We compared levels of each cytokine between TMD subgroups and controls using analysis of variance. For exploratory purposes, we set 
the level of significance at $P<.10$. Using this criterion, we identified 7 cytokines that were associated with case status and then used to construct the index for inflammatory domain measures (IL-6, MCP-1, MIP-1 $\beta$, VEGF, Tpo, FGF, and IL-1ra).

Psychological Domain Measures-All subjects completed a battery of psychological inventories that have been shown to be associated with TMD and other persistent pain conditions. ${ }^{8,67,76,82}$ Multiple measures were selected to evaluate the multiple aspects of psychological function that may contribute to "enhanced psychological distress." 20

Spielberger State-Trait Anxiety Inventory: The Spiel-berger State-Trait Anxiety Inventory (STAI) includes two 20-item instruments measuring situational state anxiety (STAI-1) and trait anxiety (STAI-2). It includes statements such as "I feel calm" or "I am worried" with response options scored on a 4-point scale from 1 (not at all) to 4 (very much so). Ten of the items are reverse scored to create an overall score of anxiety for each of the instruments. ${ }^{70,71}$

Symptom Checklist-90 Revised: The Symptom Checklist-90 Revised (SCL-90-R) consists of 90 items, each describing a feeling or thought, scored on a 5-point scale from 1 (not at all distressed) to 5 (extremely distressed). It provides ratings of psychological distress in 9 symptom areas: somatization, obsessive-compulsive, interpersonal sensitivity, depression, anxiety, hostility, phobic anxiety, paranoid ideation, and psychoticism. ${ }^{16}$ Only the depression subscale was presented and analyzed in this study.

Pain Catastrophizing Scale: The Pain Catastrophizing Scale (PCS) consists of 14 thoughts or feelings, including anxiety, coping, and helplessness in response to pain. Subjects rate the degree to which they experience each item while feeling pain using a 5-point scale from 0 (not at all) to 4 (all the time). ${ }^{73}$

Pennebaker Inventory of Limbic Languidness: The Pennebaker Inventory of Limbic Languidness (PILL) assesses the frequency of occurrence of 54 common physical symptoms and sensations using a 5-point scale, ranging from 1 (never or almost never have) to 5 (more than once every week). The total score of PILL represents somatic awareness. It has high internal consistency and sufficient test-retest reliability. ${ }^{50}$

\section{Data Reduction and Statistical Analysis}

\section{Data Reduction and Generating a Multisystem Dysregulation Index (MDI)-}

Originally, 25 markers from the 4 domains were compared between TMD subgroups (with different numbers of comorbid pain conditions) and controls using analysis of variance for continuous variables and Pearson chi-square test for categorical variables. For exploratory purpose, we determined the level for significance at $P<.10$ for selecting measures to construct each domain index, as well as a multisystem index. This yielded a total of 20 measures from the 4 domains, which include the following: 1) sensory domain: heat pain temporal summation, heat pain tolerance, PPT, and WPT; 2) autonomic domain: SBP, DBP, HR, and RPP; 3) inflammatory domain: IL-6, MCP-1, MIP-1 $\beta$, VEGF, Tpo, FGF basic, and IL-1ra; and 4) psychological domain: state (STAI-1) and trait (STAI-2) anxiety, depression (SCL-90-R-Depress), pain catastrophizing (PCS), and somatic symptom complaints (PILL).

To assess whether impairments or dysregulation in or across domains were associated with TMD and TMD with comorbidities, we adopted Seeman's (2001) multi-system dysregulation risk estimation method that was developed to concurrently measure elevated risk for dysregulation across multiple interconnected physiological systems in health research. ${ }^{64}$ This method uses the summation of several biomarkers within "elevated-risk" 
domains to indicate the magnitude of impairment or dysregulation. In the present study, impairment was assumed when 1) the value of an individual's biomarker or psychological test was at or above the 75th percentile relative to controls for heat pain temporal summation, SBP, DBP, HR, RPP, IL-6, MCP-1, MIP-1 $\beta$, VEGF, Tpo, FGF, STAI-1, STAI-2, SCL-90-R-Depress, PCS, and PILL; or 2) the value was at or below the 25th percentile relative to the controls for heat pain tolerance, PPT, and IL-1ra; and 3) with the presence of WPT. A dichotomous ( 0 or $1,0=$ no risk and $1=$ at risk) risk score was assigned to each of the 20 measures. For each participant, the total multisystem dysregulation index (MDI $\mathrm{Ttal}_{\text {tal }}$ ) was calculated as the sum of the number of markers (ie, biomarkers and psychological tests) in the defined risk zones. The risks for domain-specific dysregulation (ie, $\mathrm{MDI}_{\text {sensory }}$ for sensory domain, $\mathrm{MDI}_{\text {autonomic }}$ for autonomic domain, $\mathrm{MDI}_{\text {inflammatory }}$ for inflammatory domain, and $\mathrm{MDI}_{\text {psychological }}$ for psychological domain) were calculated as the sum of the number of measures in the risk zone in each corresponding domain.

Statistical Analyses-For statistical analyses, Stata for Windows (version 11; Stata Corp, College Station, TX) was used. Descriptive statistics for demographic and clinical characteristics, as well as for MDI total score and individual domain scores, were calculated. Statistical significance was evaluated using analysis of variance or Student t-test for continuous variables and Pearson chi-square test for categorical variables. The relationship between total MDI score and occurrence of TMD and the relationship between each MDI individual domain score and occurrence of TMD were expressed as odds ratios, calculated from logistic regression models adjusted for covariate of age. A multinomial logistic regression model was used to generate age-adjusted estimate of the relationship between total MDI score and TMD subgroup status (with different numbers of comorbid pain conditions). Additional multinomial logistic regression models were generated to estimate the relationship between an individual MDI domain and TMD subgroup status adjusted for other MDI domains and age. Bonferroni correction was used to determine the threshold for statistical significance according to the number of comparisons: $P<.001$ for demographic and clinical pain characteristics; $P \leq 002$ for multisystem dysfunction (MDI) measures and for the rejection of null hypothesis regarding odds ratios.

\section{Results}

A total of 131 controls and 159 TMD cases were identified in this study of females aged 18 to 60 years (mean $=33.4$ years, standard deviation $[\mathrm{SD}]=12.3$ years). Among TMD cases, 14 individuals reported no comorbid persistent pain condition (ie, TMD only group), 78 individuals reported 1 comorbid persistent pain condition (ie, TMD + 1 pain group), and 67 individuals reported multiple (ie, 2 or more) comorbid persistent pain conditions (ie, TMD + $\geq 2$ pain group). Significant age differences were found between controls and TMD cases, and among TMD subgroups with different numbers of comorbid pain conditions (Table 1, $P$ S $<.001)$.

\section{Clinical Pain Characteristics}

Morethan $90 \%$ of TMD subjects fulfilled RDC/TMD diagnosis criteria for both myalgia and arthralgia (Table 1). On average, TMD subjects reported $9.5 \pm 8.3$ years of facial pain. Facial pain intensity was at "moderate" (midscale) levels during the past 6 months (Table 1). Overall, 50 to $60 \%$ of TMD subjects reported high intensity and/or high disability (ie, GCPS levels II-IV) from facial pain in the past 6 months (Fig 1). TMD cases also reported an average of $52 \%$ of waking days with "mild to moderate" levels of "head, neck, or facial pain" in the past 1 to 2 weeks. After Bonferroni correction, no differences among TMD 
subgroups (ie, TMD only, TMD + 1 pain, TMD $+\geq 2$ pain) were observed in any facial pain intensity, unpleasantness, or severity measures (Table 1 and Fig 1).

In addition, $6 \%$ of controls and $65 \%$ of TMD subjects reported pain from nonfacial regions in the past 6 months (ie, GCPS other pain, $P<.001$ ). Although none of the controls reported high pain intensity and/or high disability from nonfacial pain, 38\% of TMD cases reported high pain intensity and/or high disability (ie, GCPS levels II-IV) from pain in nonfacial regions. The highest proportion (59\%) was observed in the subgroup of TMD with multiple comorbid pain conditions $(P<<.001$, Fig 1$)$.

\section{Comorbid Persistent Pain Conditions}

The most prevalent comorbid persistent pain condition reported by TMD cases was frequent headaches (ie, $84 \%$ in all TMD cases; Table 2). For the majority (91\%) of cases with 1 comorbid pain, frequent headache was their only comorbid pain condition. Among those cases with multiple comorbid pain conditions, frequent headache was reported by almost every participant (99\%). Fibromyalgia, IBS, and frequent low back pain were also highly prevalent in the TMD subgroup with multiple comorbid pain conditions (Table 2).

\section{Multisystem Dysregulation Measures}

A total of 25 markers from 4 system domains were initially measured (ie, sensory, autonomic, inflammatory, and psychological; see Supplementary Tables 1-4). After exploratory analysis, 20 markers with significant difference between controls and cases were selected to construct the multisystem dysregulation index, generating an overall risk score for multisystem dysregulation ( $\mathrm{MDI}_{\text {total }}$ ) ranging from 0 to 20 (see Data Reduction section for detailed description). Bivariate analysis showed that on average, the $\mathrm{MDI}_{\text {total }}$ score was greater in TMD subjects than in controls (mean $\pm \mathrm{SD}=8.6 \pm 3.0$ vs $4.9 \pm 2.5$, respectively, $P \leq 001$, Table 3 ). When further compared between each TMD subgroup and controls, $\mathrm{MDI}_{\text {total }}$ scores were elevated in all $3 \mathrm{TMD}$ subgroups after Bonferroni correction $(P \mathrm{~s} \leq$. 002; Table 3).

TMD cases as a group also showed greater MDI domain scores in all 4 system domains as compared to controls $\left(P_{\mathrm{S}} \leq .001\right.$; Table 3$)$. However, individual MDI system domain scores showed selective elevation in different TMD subgroups with different numbers of comorbid pain conditions. Sensory domain score (MDI $\left.{ }_{\text {sensory }}\right)$ was greater in all TMD subgroups than in controls, autonomic domain score $\left(\mathrm{MDI}_{\text {autonomic }}\right)$ and inflammatory domain score $\left(\mathrm{MDI}_{\text {inflammatory }}\right)$ were only elevated in the subgroup of $\mathrm{TMD}+\geq 2$ pain conditions, and psychological domain score ( MDI $\left._{\text {psychological }}\right)$ was elevated in the subgroups of TMD +1 pain and of TMD $+\geq 2$ pain conditions $(P \mathrm{~S} \leq .002$; Table 3$)$.

\section{Multivariate Analyses of the Association Between MDI Scores and TMD Case Status}

Multivariate analyses showed an overall contribution of multisystem dysregulation (MDI $\left.{ }_{\text {total }}\right)$, as well as selective contributions from individual system domains to painful TMD (Table 4). After adjustment for age, each 1 unit increase in MDI $_{\text {total }}$ score (ie, 1 additional dysregulation from any assessed biomarkers or psychological tests) was associated with 1.6 times the odds of being a TMD case $(95 \%$ confidence interval $[\mathrm{CI}]=$ 1.4-1.8, $P<.001$; Table 4, Model 1). After adjustment for age and for other MDI system domains, each 1 unit increase in $\mathrm{MDI}_{\text {sensory }}$ or $\mathrm{MDI}_{\text {psychological }}$ domain scores (ie, 1 additional dysregulation from any assessed sensory or psychological measures) was associated with approximately 2 times the odds of being a TMD case $(P \leq .001$; Table 4 , Model 2). The contributions from autonomic domain and inflammatory domain were not independent (Table 4, Model 2). 
To further explore the relationship between total multisystem dysregulation and the classification of 3 TMD subgroups with different numbers of comorbid pain conditions, multinomial logistic regression analyses were performed with adjustment for age. The results showed that increase in $\mathrm{MDI}_{\text {total }}$ score was associated with increased odds for being a TMD case in any subgroups compared to controls ( $\mathrm{OR}$ [odds ratio] $=1.5,95 \% \mathrm{CI}=1.2-2.0$; $\mathrm{OR}=1.5,95 \% \mathrm{CI}=1.3-1.7 ;$ and $\mathrm{OR}=1.8,95 \% \mathrm{CI}=1.5-2.2$, for TMD only, $\mathrm{TMD}+1$ pain and TMD $+\geq 2$ pain, respectively, $P \leq .002 ;$ Fig 2 )

However, dysregulation in each individual system domain was associated differently with the odds of being in a specific TMD subgroup after adjustment for age and for the contribution from other system domains (Figs 3-6). Each 1 unit increase in MDI $_{\text {sensory }}$ score (ie, 1 additional dysregulation from any assessed sensory measures) was associated with 2.8 times the odds for being a TMD case with multiple comorbid pain conditions $(95 \% \mathrm{CI}=$ 1.7-4.7, $P \leq 001$; Fig 3). A trend of association between increased $\mathrm{MDI}_{\text {sensory }}$ score and elevated odds for being a TMD case with no comorbid pain condition was seen $(\mathrm{OR}=2.6$, $95 \% \mathrm{CI}=1.2-5.4, P=.01 ; \mathrm{Fig} 3)$. However, this association did not reach statistical significance after Bonferroni correction for multiple comparisons ( $P \leq 002$ was required for MDI measures).

No association was seen between $\mathrm{MDI}_{\text {sensory }}$ score and the odds for being a TMD case with 1 pain condition $(P>.05)$.

With respect to the autonomic domain, a trend of association was seen between increased $\mathrm{MDI}_{\text {autonomic }}$ score and elevated odds for being a TMD case with multiple comorbid pain conditions (Fig 4). However, this association was not significant after Bonferroni correction $(\mathrm{OR}=1.5,95 \% \mathrm{CI}=1.1-2.0, P=.01)$. No associations were seen between $\mathrm{MDI}_{\text {sensory }}$ score and the odds for being a TMD case in the other 2 TMD subgroups.

In the inflammatory domain, no significant association between $\mathrm{MDI}_{\text {inflammatory }}$ score and the odds for being a TMD case was seen in any TMD subgroups with different comorbid pain profiles (Fig 5).

In the psychological domain, each 1 unit increase in $\mathrm{MDI}_{\text {psychological }}$ score was associated with 2 or more times the odds for being a TMD case with 1 or with multiple comorbid pain conditions $(\mathrm{OR}=2.0,95 \% \mathrm{CI}=1.6-2.6$, and $\mathrm{OR}=2.5,95 \% \mathrm{CI}=1.8-3.4$, respectively, $P \mathrm{~s}$ $<.001$; Fig 6). No association was seen between $\mathrm{MDI}_{\text {psychological }}$ score and the odds for being a TMD case without comorbid pain conditions $(\mathrm{OR}=1.6,95 \% \mathrm{CI}=1.0-2.6, P=.05)$.

\section{Discussion}

\section{Main Results}

The present study explored the relationship between multiple system dysregulation in sensory, autonomic, inflammatory, and psychological domains and painful TMD. The results revealed that 1) dysregulation in multiple system domains, particularly in the sensory and the psychological domains, were associated with increased likelihood of being a painful TMD case in general and 2) dysregulations in individual system domains selectively contribute to the increased odds of being a TMD case with different levels of comorbid persistent pain conditions. These outcomes indicate that heterogeneous multisystem dysregulations may exist in painful TMD subgroups with different numbers of comorbid pain conditions, and multidimensional physiological and psychological assessments can provide important information regarding pathophysiology, diagnosis, and management of pain in TMD patients. These findings are consistent with the heuristic model proposed by Diatchenko et al ${ }^{17}$ and Maixner et al. ${ }^{39}$ 


\section{Multisystem Dysregulation in Painful TMD}

Extensive evidence has shown dysregulations in multiple physiological and psychological system domains that associate with painful TMD. ${ }^{17,39}$ However, assessing the dysregulation in 1 specific domain fails to capture the heterogeneous phenotypes and comorbid conditions associated with painful TMD conditions. In the present study, we quantitatively measured multiple system domains (ie, sensory, autonomic, inflammatory, and psychological) that potentially contribute to painful TMD and its associated comorbid pain conditions. In addition, for each assessed system domain, we selected multiple components as each of these components may contribute to the overall dysregulation in a particular domain. ${ }^{20,25,40}$ The current selection of domain markers represents a "work-in-progress," and additional methodological development is required to identify the best predictive markers of dysregulation and subgroup classification; however, the current results demonstrate several interesting points regarding the heterogeneity of system dysregulation that manifest as a mosaic of intermediate phenotypes (eg, signs and symptoms) associated with painful TMD.

First, when the entire sample of TMD cases is considered as 1 group, the total dysregulation from multiple system domains ( $\mathrm{MDI}_{\mathrm{total}}$ ) is elevated, which is a result of increases in the assessed values in both the sensory and psychological domains. These results are consistent with previous findings that enhanced pain sensitivity and psychological distress are important risk domains for TMD (for reviews, see Diatchenko et $\mathrm{al}^{17}$ and Maixner et $\mathrm{al}^{39}$ ) and further support the multidimensional biopsychosocial assessment for painful TMD.

For the domains that failed to show significant differences between cases and controls, the interpretation should be viewed with caution. Because of secondary analysis, our selections of autonomic domain measures were limited and may not represent the most sensitive measures for autonomic function. Improved measures, such as using heart rate variability, ${ }^{63,72}$ may provide better understanding of sympathetic and parasympathetic functions in chronic pain conditions. Recent studies of autonomic function in TMD ${ }^{40}$ and related pain conditions ${ }^{10,43,60}$ support such an approach. Furthermore, our result revealed potential subgroup differences in autonomic function, with the most predominant autonomic changes seen in TMD with multiple comorbid conditions. Such heterogeneity may affect the overall group-level differences between cases and controls.

With respect to the inflammatory domain, our selected inflammatory markers did not differ between cases and controls in the multivariate analysis after adjustment for age and other MDI domains (Table 4, Model 2). This may indicate that the contribution from the inflammatory domain to TMD pain is not independent, and additional analyses that explore interactions between various risk domains are warranted. In addition, although we did not compare between TMD subgroups because of the sample size, the inflammatory profiles tended to be different among the TMD subgroups (Supplementary Tables 3a and 3b). For example, TMD cases with comorbid pain conditions exhibited general trends of elevated levels of 7 (out of 11) cytokines (IL-6, IL-8, TNF-a, MCP-1, ENA-78, FGF basic, and G$\mathrm{CSF}$ ) compared to TMD without comorbid pain conditions. This finding is consistent with the large body of literature demonstrating that elevated circulating cytokine levels are associated with widespread pain disorders. $3,28,68,69,83,90$ On the other hand, the majority (50\%-60\%) of TMD without comorbid pain conditions showed high VEGF and/or Tpo levels, and $43 \%$ of this group also showed low IL-1ra levels. These patterns were not seen in the other TMD subgroups and were novel and unexpected. On closer examination, we found that cases with TMD alone particularly showed generalized mechanical hyperalgesia. In animal models, mechanical hyperalgesia is associated with increased VEGF levels, ${ }^{36,45}$ and IL-1ra blocks mechanical hyperalgesia produced by proinflammatory cytokines. ${ }^{15}$ Thus, although a great deal of redundancy and pleiotropy exist in cytokine networks, VEGF is likely a specific marker of mechanical hyperalgesia, and subgroup differences may affect the 
overall group-level comparison between cases and controls and require further investigation with a larger sample. Nevertheless, our results highlight the importance in assessing dysregulation in multiple system domains in addition to the Axis I masticatory system when searching for pathophysiological mechanisms that promise to guide mechanism-based interventions for painful TMD.

Second, when TMD cases were stratified by bodily pain profiles, heterogeneity in multisystem dysregulation was seen in TMD subgroups. For those with painful TMD but without comorbid persistent pain conditions, the predominant dysregulation was present only in the sensory domain. This group consists of $8 \%$ of our cases with a mean age of 34 years. On average, approximately 2 (out of 4) measures in MDI sensory domain were above the risk cutoffs including both mechanical and thermal modalities (Table 2 and Supplementary Table 1a). Although this is a small group with only 14 cases, the inter subject variations were fairly small for all sensory measures (Supplementary Table 1a), indicating robust changes in this group. Our selected sensory testing sites and sensory measures permitted the assessment of the presence of a generalized somatic sensitization resulting from either peripheral or central nervous system mechanisms. Among the 3 TMD subgroups, this group showed the most extensive signs of sensory sensitization; that is, in each sensory measure, about 40 to $50 \%$ of the subjects showed elevated risk of dysregulation (Supplementary Table 1b). Although the association between sensory dysregulation ( $\mathrm{MDI}_{\text {sensory}}$ ) and the odds for being a case in this group did not reach significance in the multivariate model $(P=.01$; Fig 3$)$, we suspect this was due to the small sample size in the multivariate model $(n=9)$. In addition, having similar facial pain profiles and being of similar age as TMD cases with 1 comorbid pain group indicates that this group may have an endogenous protective mechanism(s) that protects from other comorbid pain conditions or this group may not have experienced the same pathologic exposures that contributes to the manifestation of associated comorbid conditions. Among the 3 TMD subgroups, this group had a psychological profile most similar to controls. Whether psychological resilience and a positive life history plays a protective role in this group remains an interesting and open question.

For those with painful TMD and with 1 comorbid persistent pain condition, psychological dysregulation was the only domain associated with increased likelihood for being a case. This group consisted of almost half of our cases with a mean age of 33 years. In general, subjects in this group show multiple and heterogeneous dysregulation in the psychological domain. On average, each individual has approximately 3 (out of 5) values in the psychological domain above the risk cutoff (Table 2 and Supplementary Table 4a). For each psychological test, the proportion of subjects above the risk cutoffs varied from 44 to $72 \%$ (Supplementary Table 4b). This highlights the importance of multidimensional assessment in psychosocial distress in TMD pain ${ }^{20}$ and emphasizes the importance of improving psychological well-being in managing painful TMD patients. In addition, we noticed that more than $90 \%$ of this group reported "frequent headaches" as their only comorbid persistent pain condition (Table 2). Therefore, the majority of this group still only reported localized pain in the craniofacial region. The sensory test results for this group were similar to those for controls, which do not show signs of enhanced pain sensitivity (Fig 3 and Supplementary Table 1a). Because participants in the TMD +1 pain (headache) group were on average 7 years younger than TMD cases with multiple comorbid conditions, future research should explore whether this younger group is predisposed to developing other comorbid pain conditions such as chronic widespread pain, which is associated with high levels of psychological distress. ${ }^{26}$ If so, preemptive interventions can be developed and implemented as preventive interventions. 
For those with painful TMD and multiple comorbid persistent pain conditions, a multisystem dysregulation was observed. Compared with controls, elevated dysregulation in both sensory and psychological domains as well as a trend of greater dysregulation in the autonomic domain was observed. This group consists of $42 \%$ of our cases with a mean age of 41 years. Similar to the other TMD subgroups, this group also showed heterogeneity in both $\mathrm{MDI}_{\text {sensory }}$ (31-67\% above risk cutoffs; Supplementary Table 1b) and $\mathrm{MDI}_{\mathrm{psychological}}$ (48-94\% above risk cutoffs; Supplementary Table 4b) domains. The most predominantly dysregulated measure was widespread palpation tenderness $(67 \%)$ and somatic symptom complaints $(94 \%)$. These results are consistent with previous findings on widespread pain conditions. . $^{51,57,88}$ In addition, although the difference of overall autonomic domain measure did not reach a level of significance, more than $50 \%$ of this group had elevated resting arterial blood pressure and $37 \%$ showed elevated resting heart rate values. Extensive evidence has shown autonomic dysregulation in TMD and related pain conditions such as in fibromyalgia, IBS, and CFS.7,22,40,41,43,72,79,87 In this study, the prevalence of these comorbid pain conditions ranged from $23 \%$ (CFS) to $48 \%$ (IBS) in this TMD subgroup (Table 2). Improved autonomic measures, such as using heart rate variablilty, may improve the assessment for autonomic dysfunction in this TMD subgroup.

\section{Implications and Limitations}

Heterogeneity in systemic pain profiles (ie, comorbid pain) has been clearly demonstrated in TMD populations previously. ${ }^{52,53}$ Our results are consistent with previous findings and demonstrate heterogeneous dysregulation in multiple system domains among those with different comorbid pain profiles in painful TMD. These results may reflect heterogeneous pathophysiologies associated with different regulatory domains in TMD subgroups with different numbers of comorbid pain conditions. Averaging across these subgroups may result in inaccuracy in determining the specific pathophysiological mechanisms that contribute to an individual TMD patient's signs and symptoms. Therefore, recognizing further subgroup differences is clearly possible and warrants additional methodological development and investigation.

It is well known that multiple regulatory domains such as sensory, autonomic, immuneinflammatory, and psychological domains can all contribute to peripheral and/or central pain amplification. Furthermore, these regulatory domains are often interconnected and integrated by the CNS, including CNS processes that modulate pain processing, in a manner that maintains homeostasis under normal physiological conditions. ${ }^{14,44}$ In this context, the impact from multiple interconnected regulatory domains may individually and/or collectively contribute to enhanced pain states and therefore should be assessed concurrently in examining pain perception. Currently the examination of painful TMD is focused on the structure and function of the masticatory system (Axis I), which underestimates the contribution from other pain-related modulatory domains and does not provide a full understanding of the underlying mechanisms that contribute to painful TMD and related conditions. Our results support the need to assess multiple system domains involved in pain regulation when evaluating complex persistent pain conditions like TMD. The optimal measures for this approach, as well as the clinical significance regarding treatment outcomes, require further development and exploration.

There are several limitations of this study. First, the sample size, particularly in certain TMD subgroups, is relatively small, which limited our ability to fully explore all the hypotheses. Future study design should consider equal sample size for each TMD subgroup. Second, this is a secondary data analysis using measures from a limited data set. Several issues are affected by this limitation. For example, the cohort was limited to Caucasian females, psychological or cognitive functions that might influence the subjects' ability to rationally interpret study questions and study demands were not assessed, and some measures (eg, 
measures in autonomic domain) were of an incomplete set. In addition, although the risk of chronicity is of significance for understanding and managing any chronic pain conditions, this issue could not be completely addressed because of the sample size limitation and the lack of information on chronicity of comorbid pain conditions. Furthermore, the dysregulation risk cutoffs were set arbitrarily, and the extent to which these cutoffs reflect clinical significance or subclinical risk requires additional investigation. However, to our knowledge, this is the first study that concurrently assesses pain-related multisystem dysregulation and therefore may provide valuable information on methodology and future models. Further prospective studies are needed to address these limitations.

\section{Summary}

Overall, the assessment of multiple physiological systems is critical to our understanding of the pathophysiological processes that contribute to painful TMD and associated comorbid conditions, which will ultimately guide and inform appropriate treatment strategies that address the multisystem dysregulation associated with complex and common persistent pain conditions.

\section{Supplementary Material}

Refer to Web version on PubMed Central for supplementary material.

\section{Acknowledgments}

This study was supported by NIH/NIDCR grants DE016558, NS045685, PO1 NS045685-061 A, T32-DE017245, and UO1-DE017018.

\section{References}

1. Anderson GC, Gonzalez YM, Ohrbach R, Truelove EL, Sommers E, Look JO, Schiffman EL. The Research Diagnostic Criteria for Temporomandibular Disorders. VI: Future directions. J Orofac Pain. 2010; 24:79-88. [PubMed: 20213033]

2. Atkinson G, Leary AC, George KP, Murphy MB, Jones H. 24-hour variation in the reactivity of rate-pressure-product to everyday physical activity in patients attending a hypertension clinic. Chronobiol Int. 2009; 26:958-973. [PubMed: 19637053]

3. Bazzichi L, Rossi A, Massimetti G, Giannaccini G, Giuliano T, De Feo F, Ciapparelli A, Dell'Osso L, Bombardieri S. Cytokine patterns in fibromyalgia and their correlation with clinical manifestations. Clin Exp Rheumatol. 2007; 25:225-230. [PubMed: 17543146]

4. Bragdon EE, Light KC, Costello NL, Sigurdsson A, Bunting S, Bhalang K, Maixner W. Group differences in pain modulation: Pain-free women compared to pain-free men and to women with TMD. Pain. 2002; 96:227-237. [PubMed: 11972994]

5. Bruehl S, Chung OY, Ward P, Johnson B, McCubbin JA. The relationship between resting blood pressure and acute pain sensitivity in healthy normotensives and chronic back pain sufferers: The effects of opioid blockade. Pain. 2002; 100:191-201. [PubMed: 12435472]

6. Bruehl S, Chung OY. Interactions between the cardiovascular and pain regulatory systems: An updated review of mechanisms and possible alterations in chronic pain. Neurosci Biobehav Rev. 2004; 28:395-414. [PubMed: 15341037]

7. Burton AR, Rahman K, Kadota Y, Lloyd A, Vollmer-Conna U. Reduced heart rate variability predicts poor sleep quality in a case-control study of chronic fatigue syndrome. Exp Brain Res. 2010; 204:71-78. [PubMed: 20502886]

8. Campbell LC, Riley JL 3rd, Kashikar-Zuck S, Gremillion H, Robinson ME. Somatic, affective, and pain characteristics of chronic TMD patients with sexual versus physical abuse histories. J Orofac Pain. 2000; 14:112-119. [PubMed: 11203745] 
9. Campbell RL, Langston WG. A comparison of cardiac rate-pressure product and pressure-rate quotient in healthy and medically compromised patients. Oral Surg Oral Med Oral Pathol Oral Radiol Endod. 1995; 80:145-152. [PubMed: 7552876]

10. Chalaye P, Goffaux P, Bourgault P, Lafrenaye S, Devroede G, Watier A, Marchand S. Comparing pain modulation and autonomic responses in fibromyalgia and irritable bowel syndrome patients. Clin J Pain. 2012; 28:519-526. [PubMed: 22673485]

11. Chapman CR, Tuckett RP, Song CW. Pain and stress in a systems perspective: Reciprocal neural, endocrine, and immune interactions. J Pain. 2008; 9:122-145. [PubMed: 18088561]

12. Chen H, Slade G, Lim PF, Miller V, Maixner W, Diatchenko L. Relationship between temporomandibular disorders, widespread palpation tenderness, and multiple pain conditions: A case-control study. J Pain. 2012; 13:1016-1027. [PubMed: 23031401]

13. Chung OY, Bruehl S, Diedrich L, Diedrich A. The impact of blood pressure and baroreflex sensitivity on wind-up. Anesth Analg. 2008; 107:1018-1025. [PubMed: 18713923]

14. Craig AD. A new view of pain as a homeostatic emotion. Trends Neurosci. 2003; 26:303-307. [PubMed: 12798599]

15. Davis AJ, Perkins MN. The involvement of bradykinin B1 and B2 receptor mechanisms in cytokine-induced mechanical hyperalgesia in the rat. Br J Pharmacol. 1994; 113:63-68. [PubMed: 7812634]

16. Derogatis, L. SCL-90-R Administration, Scoring \& Procedures Manual-II for the R(evised) Version and Other Instruments of the Psychopathology Rating Scales Series. Towson: Clinical Psychometric Research, Inc; 1992.

17. Diatchenko L, Nackley AG, Slade GD, Fillingim RB, Maixner W. Idiopathic pain disordersPathways of vulnerability. Pain. 2006; 123:226-230. [PubMed: 16777329]

18. Dworkin SF, LeResche L. Research Diagnostic Criteria for Temporomandibular Disorders: Review, criteria, examinations and specifications, critique. J Craniomandib Disord. 1992; 6:301355. [PubMed: 1298767]

19. Dworkin SF, von Korff MR, LeResche L. Epidemiologic studies of chronic pain: A dynamicecologic perspective. Ann Behav Med. 1992; 14:3-11.

20. Fillingim RB, Ohrbach R, Greenspan JD, Knott C, Dubner R, Bair E, Baraian C, Slade GD, Maixner W. Potential psychosocial risk factors for chronic TMD: Descriptive data and empirically identified domains from the OPPERA case-control study. J Pain. 2011; 12:T46-T60. [PubMed: 22074752]

21. Fletcher GF, Balady GJ, Amsterdam EA, Chaitman B, Eckel R, Fleg J, Froelicher VF, Leon AS, Pina IL, Rodney R, Simons-Morton DA, Williams MA, Bazzarre T. Exercise standards for testing and training: A statement for healthcare professionals from the American Heart Association. Circulation. 2001; 104:1694-1740. [PubMed: 11581152]

22. Frith J, Zalewski P, Klawe JJ, Pairman J, Bitner A, Tafil-Klawe M, Newton JL. Impaired blood pressure variability in chronic fatigue syndrome-A potential biomarker. QJM. 2012; 105:831838. [PubMed: 22670061]

23. Gracely RH. Evaluation of multi-dimensional pain scales. Pain. 1992; 48:297-300. [PubMed: 1594252]

24. Gracely RH, Lynch SA, Bennett GJ. Painful neuropathy: Altered central processing maintained dynamically by peripheral input. Pain. 1992; 51:175-194. [PubMed: 1484715]

25. Greenspan JD, Slade GD, Bair E, Dubner R, Fillingim RB, Ohrbach R, Knott C, Mulkey F, Rothwell R, Maixner W. Pain sensitivity risk factors for chronic TMD: Descriptive data and empirically identified domains from the OPPERA case control study. J Pain. 2011; 12:T61-T74. [PubMed: 22074753]

26. Gupta A, Silman AJ, Ray D, Morriss R, Dickens C, MacFarlane GJ, Chiu YH, Nicholl B, McBeth $\mathrm{J}$. The role of psychosocial factors in predicting the onset of chronic widespread pain: Results from a prospective population-based study. Rheumatology (Oxford). 2007; 46:666-671. [PubMed: 17085772]

27. Gur A, Karakoc M, Erdogan S, Nas K, Cevik R, Sarac AJ. Regional cerebral blood flow and cytokines in young females with fibromyalgia. Clin Exp Rheumatol. 2002; 20:753-760. [PubMed: 12508765] 
28. Gur A, Karakoc M, Nas K, Remzi, Cevik, Denli A, Sarac J. Cytokines and depression in cases with fibromyalgia. J Rheumatol. 2002; 29:358-361. [PubMed: 11838856]

29. Hull J, Thomson A, Kwiatkowski D. Association of respiratory syncytial virus bronchiolitis with the interleukin 8 gene region in UK families. Thorax. 2000; 55:1023-1027. [PubMed: 11083887]

30. Isong U, Gansky SA, Plesh O. Temporomandibular joint and muscle disorder-type pain in U.S. adults: The National Health Interview Survey. J Orofac Pain. 2008; 22:317-322. [PubMed: 19090404]

31. Kopp S. The influence of neuropeptides, serotonin, and interleukin 1beta on temporomandibular joint pain and inflammation. J Oral Maxillofac Surg. 1998; 56:189-191. [PubMed: 9461143]

32. Kopp S, Alstergren P, Ernestam S, Nordahl S, Morin P, Bratt J. Reduction of temporomandibular joint pain after treatment with a combination of methotrexate and infliximab is associated with changes in synovial fluid and plasma cytokines in rheumatoid arthritis. Cells Tissues Organs. 2005; 180:22-30. [PubMed: 16088130]

33. Krogstad BS, Jokstad A, Dahl BL, Vassend O. Relationships between risk factors and treatment outcome in a group of patients with temporomandibular disorders. J Orofac Pain. 1996; 10:48-53. [PubMed: 8995916]

34. Kulshreshtha P, Gupta R, Yadav RK, Bijlani RL, Deepak KK. A comprehensive study of autonomic dysfunction in the fibromyalgia patients. Clin Auton Res. 2012; 22:117-122. [PubMed: 22038566]

35. Latremoliere A, Woolf CJ. Central sensitization: A generator of pain hypersensitivity by central neural plasticity. J Pain. 2009; 10:895-926. [PubMed: 19712899]

36. Lin J, Li G, Den X, Xu C, Liu S, Gao Y, Liu H, Zhang J, Li X, Liang S. VEGF and its receptor-2 involved in neuropathic pain transmission mediated by $\mathrm{P} 2 \mathrm{X}(2)(/)(3)$ receptor of primary sensory neurons. Brain Res Bull. 2010; 83:284-291. [PubMed: 20705122]

37. Maes M, Song C, Lin A, De Jongh R, Van Gastel A, Kenis G, Bosmans E, De Meester I, Benoy I, Neels H, Demedts P, Janca A, Scharpe S, Smith RS. The effects of psychological stress on humans: Increased production of proinflammatory cytokines and a Th1-like response in stressinduced anxiety. Cytokine. 1998; 10:313-318. [PubMed: 9617578]

38. Maes M. Major depression and activation of the inflammatory response system. Adv Exp Med Biol. 1999; 461:25-46. [PubMed: 10442165]

39. Maixner W, Diatchenko L, Dubner R, Fillingim RB, Greenspan JD, Knott C, Ohrbach R, Weir B, Slade GD. Orofacial Pain Prospective Evaluation and Risk Assessment study-The OPPERA study. J Pain. 2011; 12:T4-11. e1-2. [PubMed: 22074751]

40. Maixner W, Greenspan JD, Dubner R, Bair E, Mulkey F, Miller V, Knott C, Slade GD, Ohrbach R, Diatchenko L, Fillingim RB. Potential autonomic risk factors for chronic TMD: Descriptive data and empirically identified domains from the OPPERA case-control study. J Pain. 2011; 12:T75T91. [PubMed: 22074754]

41. Martinez-Lavin M. Fibromyalgia as a sympathetically maintained pain syndrome. Curr Pain Headache Rep. 2004; 8:385-389. [PubMed: 15361323]

42. Matsumoto K, Honda K, Ohshima M, Yamaguchi Y, Nakajima I, Micke P, Otsuka K. Cytokine profile in synovial fluid from patients with internal derangement of the temporomandibular joint: A preliminary study. Dentomaxillofac Radiol. 2006; 35:432-441. [PubMed: 17082335]

43. Mazurak N, Seredyuk N, Sauer H, Teufel M, Enck P. Heart rate variability in the irritable bowel syndrome: A review of the literature. Neurogastroenterol Motil. 2012; 24:206-216. [PubMed: 22256893]

44. Melzack R. From the gate to the neuromatrix. Pain. 1999; (Suppl 6):S121-S126. [PubMed: 10491980]

45. Miyoshi S, Sekiguchi M, Konno S, Kikuchi S, Kanaya F. Increased expression of vascular endothelial growth factor protein in dorsal root ganglion exposed to nucleus pulposus on the nerve root in rats. Spine (Phila Pa 1976). 2011; 36:E1-E6. [PubMed: 21243740]

46. Nalawadi SS, Tolstrup K, Cuk O, Shiota T, Gurudevan SV, Siegel RJ. Atropine as an adjunct to supine bicycle stress echocardiography: An alternative strategy to achieve target heart rate or rate pressure product. Eur Heart J Cardiovasc Imaging. 2012; 13:612-616. [PubMed: 22271103] 
47. Nordahl S, Alstergren P, Eliasson S, Kopp S. Interleukin-1beta in plasma and synovial fluid in relation to radiographic changes in arthritic temporomandibular joints. Eur J Oral Sci. 1998; 106:559-563. [PubMed: 9527355]

48. Ogura N, Satoh K, Akutsu M, Tobe M, Kuyama K, Kuboyama N, Sakamaki H, Kujiraoka H, Kondoh T. MCP-1 production in temporomandibular joint inflammation. J Dent Res. 2010; 89:1117-1122. [PubMed: 20647497]

49. Papathanasiou G, Georgakopoulos D, Georgoudis G, Spyropoulos P, Perrea D, Evangelou A. Effects of chronic smoking on exercise tolerance and on heart rate-systolic blood pressure product in young healthy adults. Eur J Cardiovasc Prev Rehabil. 2007; 14:646-652. [PubMed: 17925623]

50. Pennebaker, J. The Psychology of Physical Symptoms. New York: Springer Verlag; 1982.

51. Petzke F, Clauw DJ, Ambrose K, Khine A, Gracely RH. Increased pain sensitivity in fibromyalgia: Effects of stimulus type and mode of presentation. Pain. 2003; 105:403-413. [PubMed: 14527701]

52. Pfau DB, Rolke R, Nickel R, Treede RD, Daublaender M. Somatosensory profiles in subgroups of patients with myogenic temporomandibular disorders and fibromyalgia syndrome. Pain. 2009; 147:72-83. [PubMed: 19767146]

53. Plesh O, Adams SH, Gansky SA. Temporomandibular joint and muscle disorder-type pain and comorbid pains in a national US sample. J Orofac Pain. 2011; 25:190-198. [PubMed: 21837286]

54. Price DD. Psychological and neural mechanisms of the affective dimension of pain. Science. 2000; 288:1769-1772. [PubMed: 10846154]

55. Rammelsberg P, LeResche L, Dworkin S, Mancl L. Longitudinal outcome of temporomandibular disorders: A 5-year epidemiologic study of muscle disorders defined by Research Diagnostic Criteria for Temporomandibular Disorders. J Orofac Pain. 2003; 17:9-20. [PubMed: 12756926]

56. Randich A, Maixner W. Interactions between cardiovascular and pain regulatory systems. Neurosci Biobehav Rev. 1984; 8:343-367. [PubMed: 6095151]

57. Raphael KG, Marbach JJ, Klausner J. Myofascial face pain. Clinical characteristics of those with regional vs. widespread pain. J Am Dent Assoc. 2000; 131:161-171. [PubMed: 10680383]

58. Raphael KG, Marbach JJ. Widespread pain and the effectiveness of oral splints in myofascial face pain. J Am Dent Assoc. 2001; 132:305-316. [PubMed: 11258087]

59. Ren K, Dubner R. Interactions between the immune and nervous systems in pain. Nat Med. 2010; 16:1267-1276. [PubMed: 20948535]

60. Reyes del Paso GA, Garrido S, Pulgar A, Duschek S. Autonomic cardiovascular control and responses to experimental pain stimulation in fibromyalgia syndrome. J Psychosom Res. 2011; 70:125-134. [PubMed: 21262414]

61. Riva R, Mork PJ, Westgaard RH, Okkenhaug Johansen T, Lundberg U. Catecholamines and heart rate in female fibromyalgia patients. J Psychosom Res. 2012; 72:51-57. [PubMed: 22200523]

62. Schiffman EL, Truelove EL, Ohrbach R, Anderson GC, John MT, List T, Look JO. The Research Diagnostic Criteria for Temporomandibular Disorders. I: Overview and methodology for assessment of validity. J Orofac Pain. 2010; 24:7-24. [PubMed: 20213028]

63. Schmidt JE, Carlson CR. A controlled comparison of emotional reactivity and physiological response in masticatory muscle pain patients. J Orofac Pain. 2009; 23:230-242. [PubMed: 19639103]

64. Seeman TE, McEwen BS, Rowe JW, Singer BH. Allostatic load as a marker of cumulative biological risk: MacArthur studies of successful aging. Proc Natl Acad Sci U S A. 2001; 98:47704775. [PubMed: 11287659]

65. Shafer DM, Assael L, White LB, Rossomando EF. Tumor necrosis factor-alpha as a biochemical marker of pain and outcome in temporomandibular joints with internal derangements. J Oral Maxillofac Surg. 1994; 52:786-791. discussion 91-2. [PubMed: 8040729]

66. Simone DA. Neural mechanisms of hyperalgesia. Curr Opin Neurobiol. 1992; 2:479-483. [PubMed: 1525546]

67. Slade GD, Diatchenko L, Bhalang K, Sigurdsson A, Fillingim RB, Belfer I, Max MB, Goldman D, Maixner W. Influence of psychological factors on risk of temporomandibular disorders. J Dent Res. 2007; 86:1120-1125. [PubMed: 17959908]

68. Slade GD, Conrad MS, Diatchenko L, Rashid NU, Zhong S, Smith S, Rhodes J, Medvedev A, Makarov S, Maixner W, Nackley AG. Cytokine biomarkers and chronic pain: Association of 
genes, transcription, and circulating proteins with temporomandibular disorders and widespread palpation tenderness. Pain. 2011; 152:2802-2812. [PubMed: 22000099]

69. Sommer C, Hauser W, Gerhold K, Joraschky P, Petzke F, Tölle T, Uçeyler N, Winkelmann A, Thieme K. Etiology and pathophysiology of fibromyalgia syndrome and chronic widespread pain [in German]. Schmerz. 22:267-282. [PubMed: 18470541]

70. Spielberger, C. State-Trait Anxiety Inventory for Adults. Palo Alto, CA: Mind Garden; 1983.

71. Spielberger, CDGR.; Lushene, R.; Vagg, PR.; Jacobs, GA. Manual for the State-Trait Anxiety Inventory (Form Y1). Palo Alto, CA: Consulting Psychologists Press; 1983.

72. Staud R. Autonomic dysfunction in fibromyalgia syndrome: Postural orthostatic tachycardia. Curr Rheumatol Rep. 2008; 10:463-466. [PubMed: 19007537]

73. Sullivan MJL, Bishop S, Pivik J. The Pain Catastrophizing Scale: Development and validation. Psychol Assess. 1995; 7:524-532.

74. Takahashi T, Kondoh T, Fukuda M, Yamazaki Y, Toyosaki T, Suzuki R. Proinflammatory cytokines detectable in synovial fluids from patients with temporomandibular disorders. Oral Surg Oral Med Oral Pathol Oral Radiol Endod. 1998; 85:135-141. [PubMed: 9503445]

75. Tominaga K, Habu M, Sukedai M, Hirota Y, Takahashi T, Fukuda J. IL-1 beta, IL-1 receptor antagonist and soluble type II IL-1 receptor in synovial fluid of patients with temporomandibular disorders. Arch Oral Biol. 2004; 49:493-499. [PubMed: 15099807]

76. Turner JA, Brister H, Huggins K, Mancl L, Aaron LA, Truelove EL. Catastrophizing is associated with clinical examination findings, activity interference, and health care use among patients with temporomandibular disorders. J Orofac Pain. 2005; 19:291-300. [PubMed: 16279480]

77. Turp JC, Kowalski CJ, O'Leary N, Stohler CS. Pain maps from facial pain patients indicate a broad pain geography. J Dent Res. 1998; 77:1465-1472. [PubMed: 9649175]

78. Uceyler N, Hauser W, Sommer C. Systematic review with meta-analysis: Cytokines in fibromyalgia syndrome. BMC Musculoskelet Disord. 2011; 12:245. [PubMed: 22034969]

79. Ulas UH, Unlu E, Hamamcioglu K, Odabasi Z, Cakci A, Vural O. Dysautonomia in fibromyalgia syndrome: Sympathetic skin responses and RR interval analysis. Rheumatol Int. 2006; 26:383387. [PubMed: 15988599]

80. Velly AM, Look JO, Schiffman E, Lenton PA, Kang W, Messner RP, Holcroft CA, Fricton JR. The effect of fibromyalgia and widespread pain on the clinically significant temporomandibular muscle and joint pain disorders-A prospective 18-month cohort study. J Pain. 2010; 11:11551164. [PubMed: 20466595]

81. Von Korff M, Ormel J, Keefe FJ, Dworkin SF. Grading the severity of chronic pain. Pain. 1992; 50:133-149. [PubMed: 1408309]

82. Von Korff M, Le Resche L, Dworkin SF. First onset of common pain symptoms: A prospective study of depression as a risk factor. Pain. 1993; 55:251-258. [PubMed: 8309712]

83. Wallace DJ, Linker-Israeli M, Hallegua D, Silverman S, Silver D, Weisman MH. Cytokines play an aetiopathogenetic role in fibromyalgia: A hypothesis and pilot study. Rheumatology (Oxford). 2001; 40:743-749. [PubMed: 11477278]

84. White WB. Heart rate and the rate-pressure product as determinants of cardiovascular risk in patients with hypertension. Am J Hypertens. 1999; 12:50S-55S. [PubMed: 10090295]

85. Wieseler-Frank J, Maier SF, Watkins LR. Immune-to-brain communication dynamically modulates pain: Physiological and pathological consequences. Brain Behav Immun. 2005; 19:104-111. [PubMed: 15664782]

86. Wolfe F, Smythe HA, Yunus MB, Bennett RM, Bombardier C, Goldenberg DL, Tugwell P, Campbell SM, Abeles M, Clark P, Fam AG, Farber SJ, Fiechtner JJ, Franklin CM, Gatter RA, Hamaty D, Lessard J, Lichtbroun AS, Masi AT, McCain GA, Reynolds WJ, Romano TJ, Russell IJ, Sheon RP. The American College of Rheumatology 1990 Criteria for the Classification of Fibromyalgia. Report of the Multicenter Criteria Committee. Arthritis Rheum. 1990; 33:160-172. [PubMed: 2306288]

87. Yoshiuchi K, Quigley KS, Ohashi K, Yamamoto Y, Natelson BH. Use of time-frequency analysis to investigate temporal patterns of cardiac autonomic response during head-up tilt in chronic fatigue syndrome. Auton Neurosci. 2004; 113:55-62. [PubMed: 15296795] 
88. Yunus MB. Central sensitivity syndromes: A new paradigm and group nosology for fibromyalgia and overlapping conditions, and the related issue of disease versus illness. Semin Arthritis Rheum. 2008; 37:339-352. [PubMed: 18191990]

89. Zamir N, Maixner W. The relationship between cardiovascular and pain regulatory systems. Ann N Y Acad Sci. 1986; 467:371-384. [PubMed: 3524385]

90. Zhang Z, Cherryholmes G, Mao A, Marek C, Longmate J, Kalos M, Amand RP, Shively JE. High plasma levels of MCP-1 and eotaxin provide evidence for an immunological basis of fibromyalgia. Exp Biol Med (Maywood). 2008; 233:1171-1180. [PubMed: 18535166] 


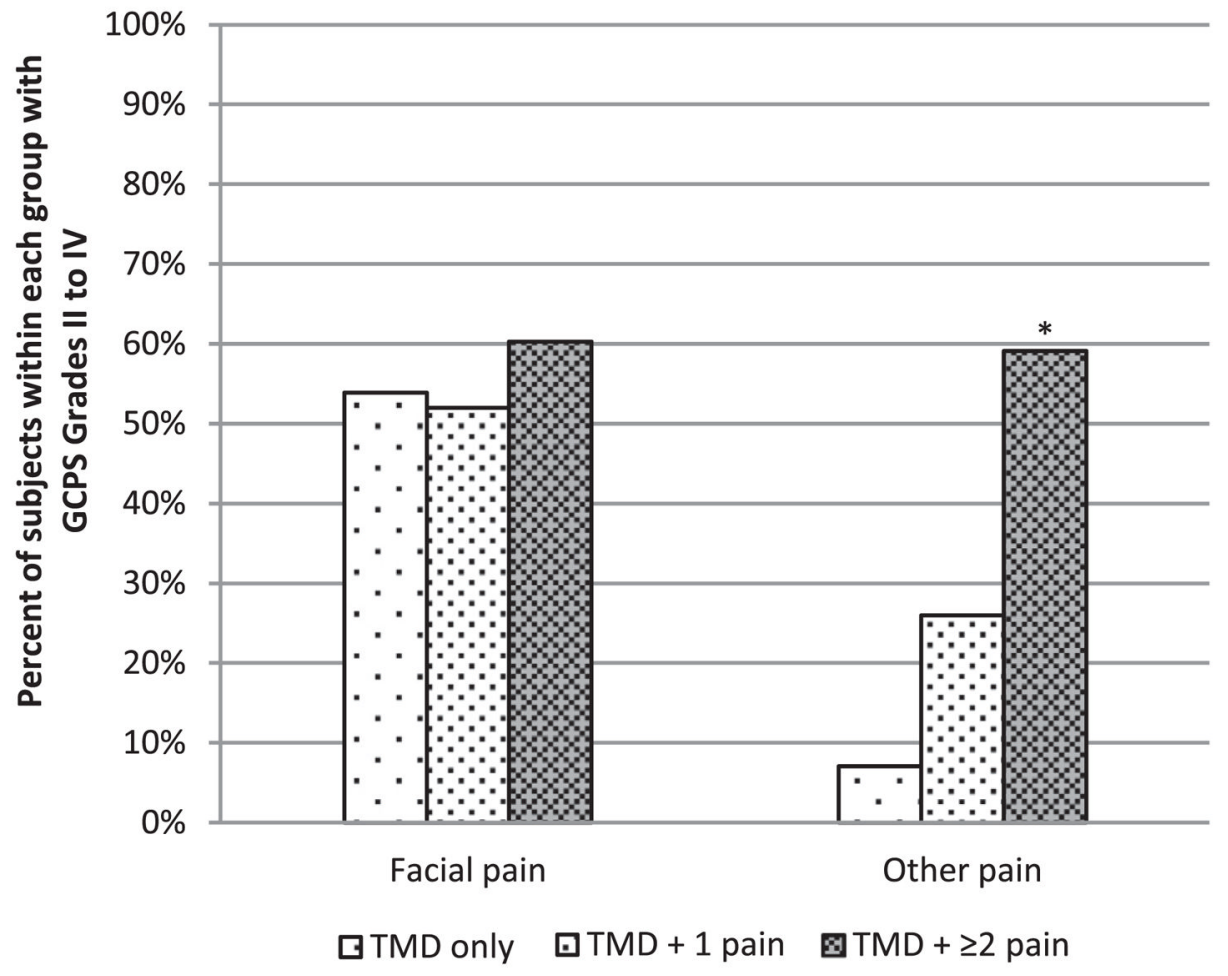

Figure 1.

Percentage of subjects within TMD subgroups with GCPS Grades II to IV at different pain locations. GCPS Grade I, low disability-low intensity; Grade II, low disability-high intensity; Grade III, high disability-moderately limiting; and Grade IV, high disabilityseverely limiting. GCPS Grades II to IV were selected to represent "clinical significant pain." $* P<.001$ for the following: TMD $+\geq 2$ pain vs TMD only; TMD $+\geq 2$ pain vs TMD +1 pain. 


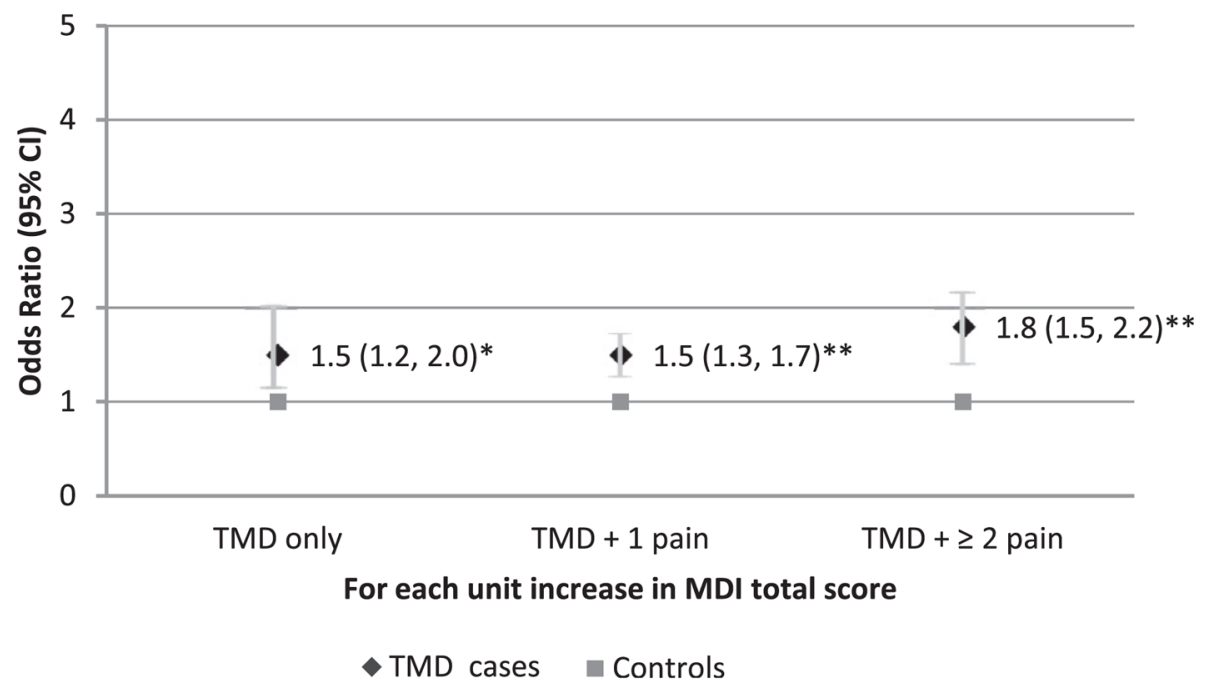

Figure 2.

Likelihood of being TMD subgroup cases by total MDI score. The MDI total score is differently associated with the odds of being TMD subgroups based on the number of comorbid persistent pain conditions. Odds ratios were calculated for each case classification relative to controls from a multinomial logistic regression model adjusted for age $(\mathrm{n}=230$ females). $* P=.002, * * P<.001$. 


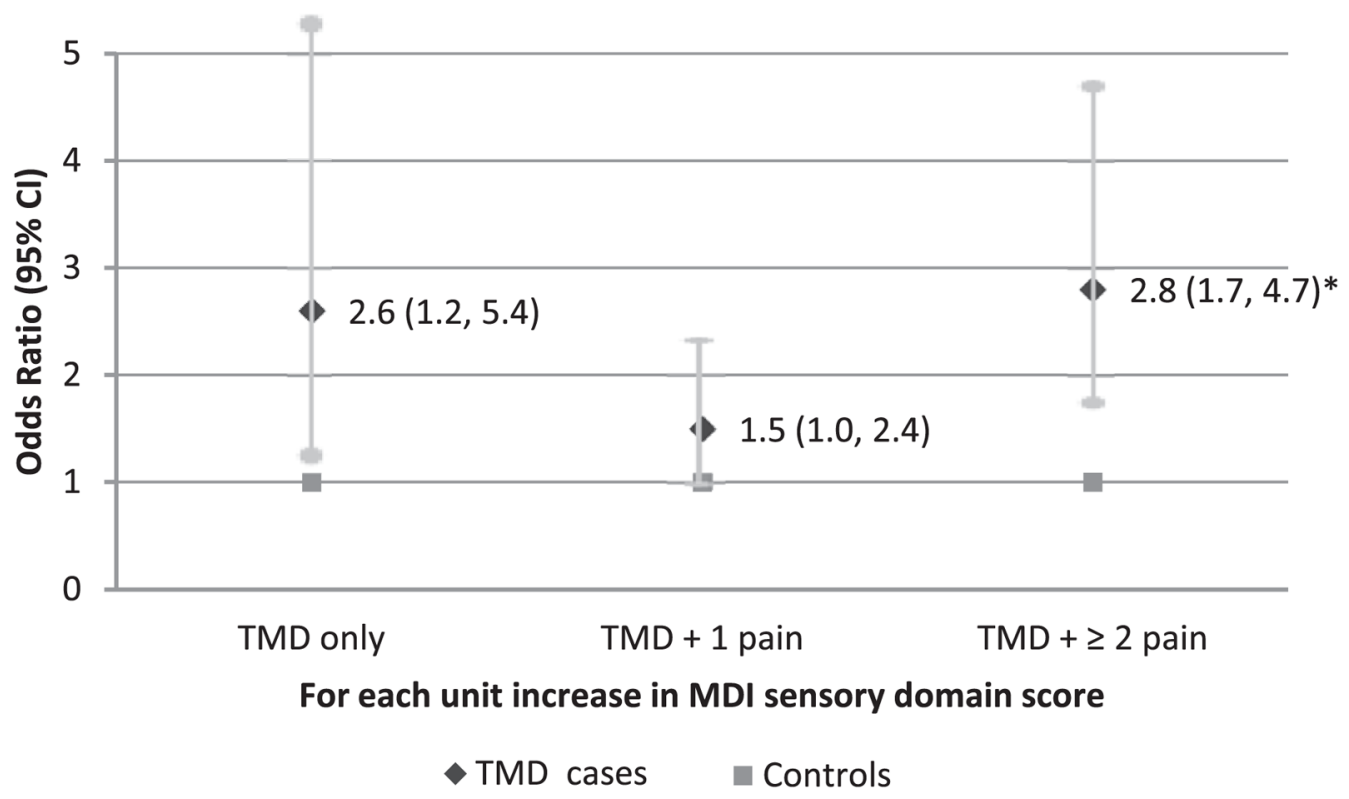

Figure 3.

Likelihood of being TMD subgroup cases by sensory domain score. The MDI sensory domain score is differently associated with the odds of being TMD subgroups based on the number of comorbid persistent pain conditions. Odds ratios were calculated for each case classification relative to controls from a multinomial logistic regression model adjusted for age and dysregulation from autonomic, inflammatory, and psychological domains $(\mathrm{n}=230$ females). $* P \leq 001$. 


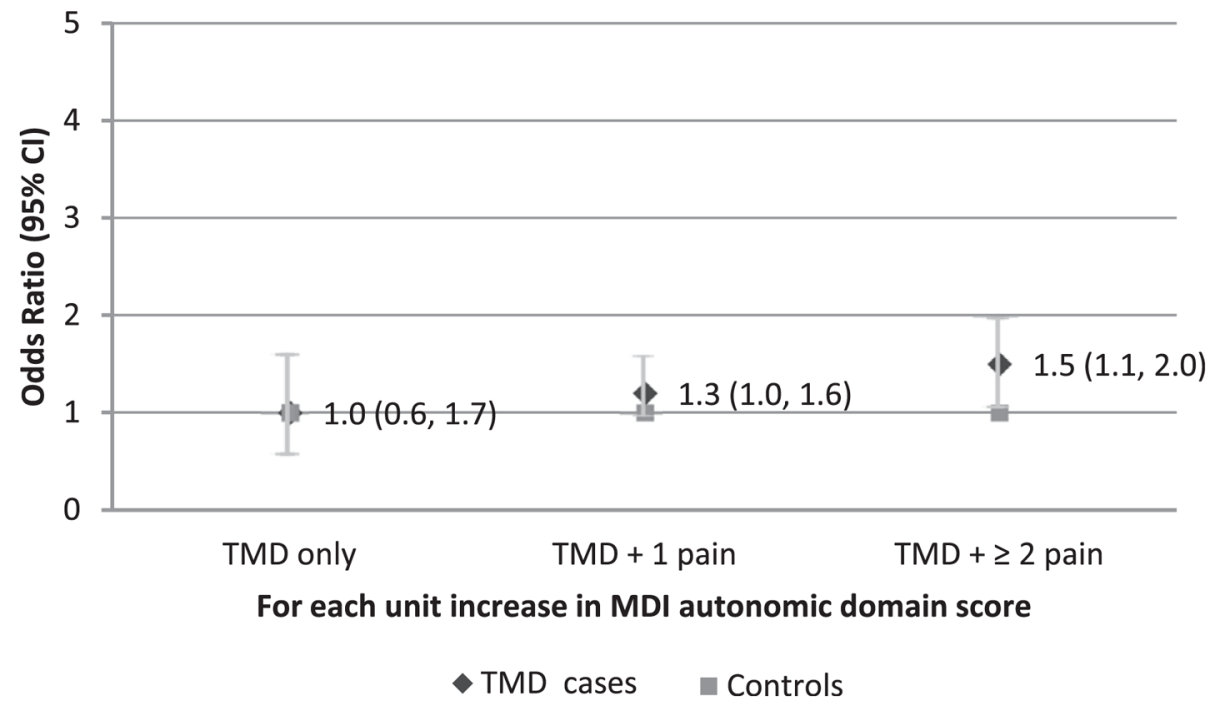

Figure 4.

Likelihood of being TMD subgroup cases by autonomic domain score. The MDI autonomic domain score is not associated with the odds of being TMD subgroups based on the number of comorbid persistent pain conditions. Odds ratios were calculated for each case classification relative to controls from a multinomial logistic regression model adjusted for age and dysregulation from sensory, inflammatory, and psychological domains $(\mathrm{n}=230$ females). 


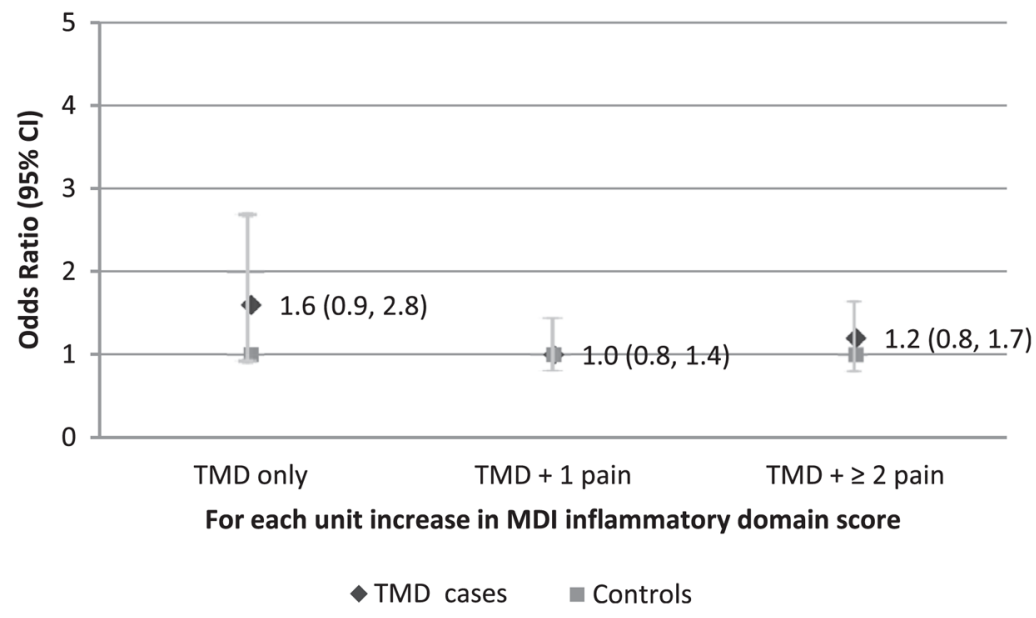

Figure 5.

Likelihood of being TMD subgroup cases by inflammatory domain score. The MDI inflammatory domain score is not associated with the odds of TMD subgroups based on the number of comorbid persistent pain conditions. Odds ratios were calculated for each case classification relative to controls from a multinomial logistic regression model adjusted for age and dysregulation from sensory, autonomic, and psychological domains $(\mathrm{n}=230$ females). 


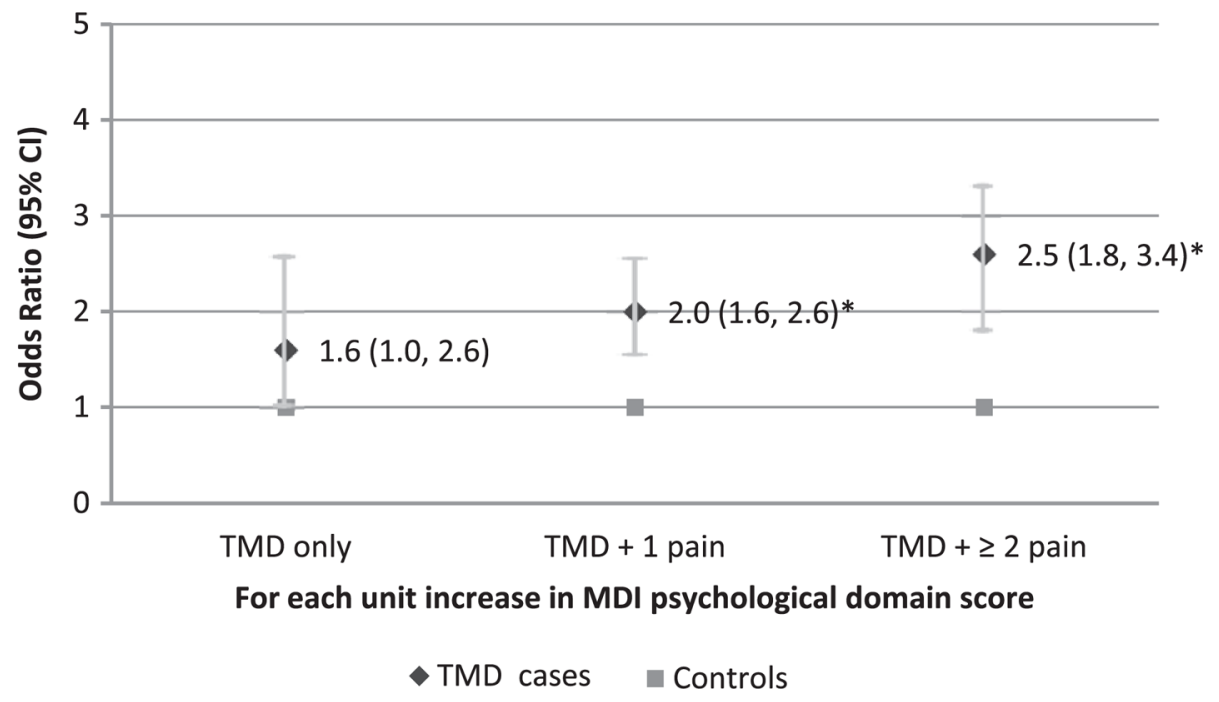

Figure 6.

Likelihood of being TMD subgroup cases by psychological domain score. The MDI psychological domain score is differently associated with the odds of TMD subgroups based on the number of comorbid persistent pain conditions. Odds ratios were calculated for each case classification relative to controls from a multinomial logistic regression model adjusted for age and dysregulation from sensory, autonomic and inflammatory domains $(\mathrm{n}=230$ females). $* P<.001$. 


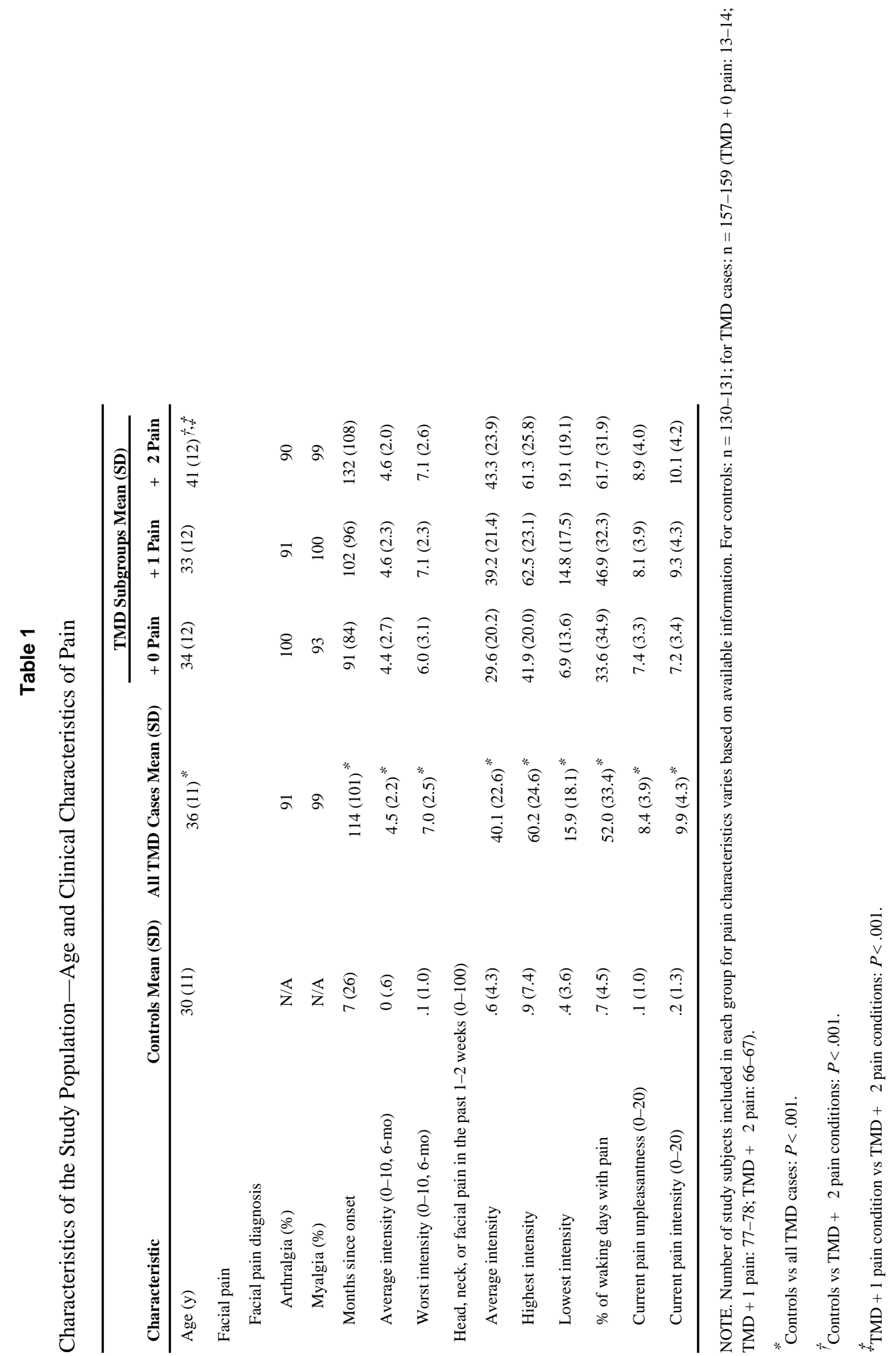


Table 2

Percentage of TMD Cases With Different Numbers of Comorbid Persistent Pain Condition(s)

\begin{tabular}{lrrr}
\hline & All TMD Cases \% & TMD + 1 Pain \% & TMD + $\geq 2$ Pain \% \\
\hline Fibromyalgia & 18 & 0 & 43 \\
Chronic fatigue syndrome & 10 & 0 & 23 \\
IBS & 23 & 5 & 48 \\
Interstitial cystitis & 1 & 0 & 3 \\
Chronic pelvic pain & 7 & 0 & 16 \\
Frequent headaches & 86 & 91 & 99 \\
Frequent low back pain & 25 & 4 & 55 \\
\hline
\end{tabular}

NOTE. Number of study subjects included in each group for comorbid pain conditions varies based on available information. For all TMD cases: $\mathrm{n}$ $=155-159 ;$ for $\mathrm{TMD}+1$ pain, $\mathrm{n}=75-78 ;$ for TMD $+\geq 2$ pain, $\mathrm{n}=65-67$. 


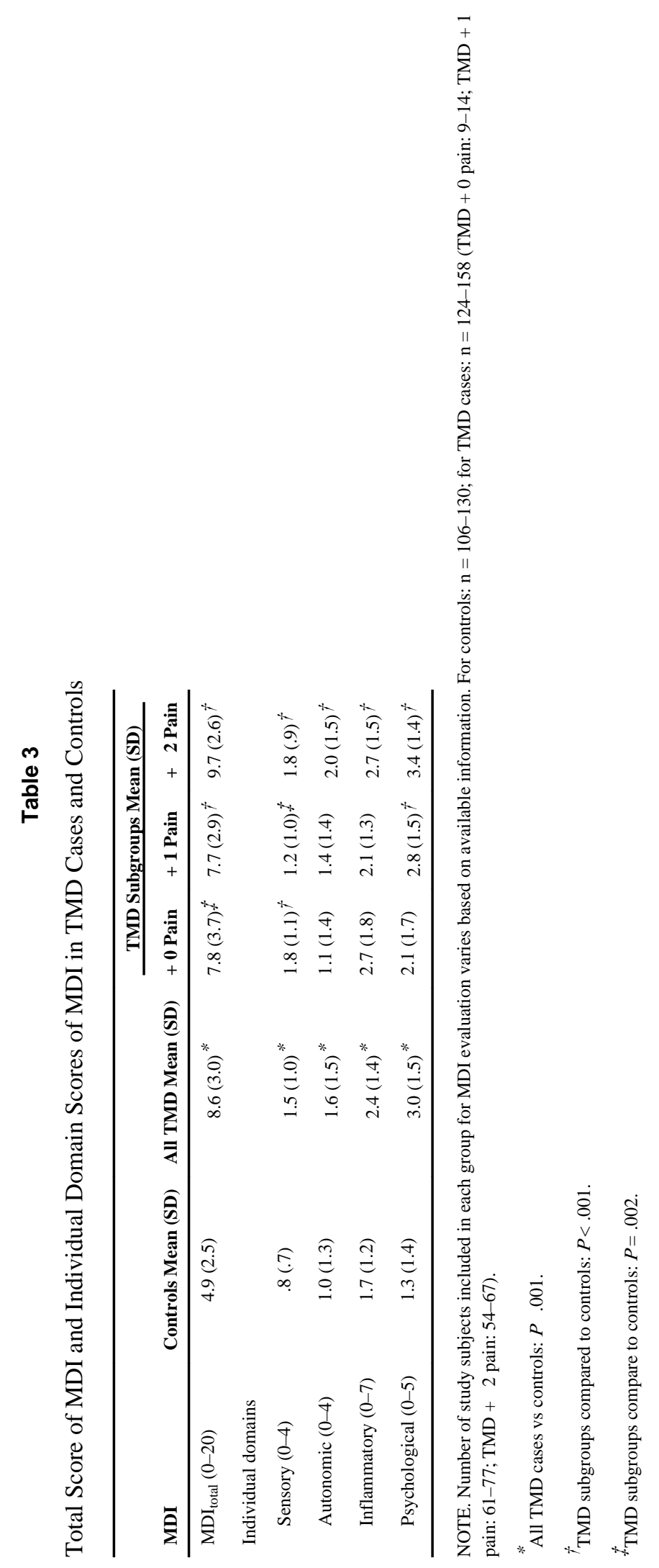

J Pain. Author manuscript; available in PMC 2014 September 01. 
Table 4

Multivariate Adjusted Odds Ratios Comparing MDI Scores and TMD Case (vs Noncase) Status

\begin{tabular}{|c|c|c|c|c|}
\hline & Model $1^{*}$ Odds Ratio (95\% CI) & $P$ value & Model $2^{\dagger}$ Odds Ratio $(95 \%$ CI) & $P$ value \\
\hline $\mathrm{MDI}_{\text {total }}$ & $1.6(1.4,1.8)$ & .000 & N/A & N/A \\
\hline \multicolumn{5}{|c|}{ Individual MDI domains } \\
\hline MDI $_{\text {sensory }}$ & N/A & N/A & $1.9(1.3,2.9)$ & .001 \\
\hline $\mathrm{MDI}_{\text {autonomic }}$ & N/A & N/A & $1.3(1.0,1.6)$ & .046 \\
\hline $\mathrm{MDI}_{\text {inflammatory }}$ & N/A & N/A & $1.1(.9,1.5)$ & .368 \\
\hline $\mathrm{MDI}_{\mathrm{psychological}}$ & N/A & N/A & $2.1(1.7,2.7)$ & .000 \\
\hline Age & $1.0(1.0,1.1)$ & .07 & $1.0(1.0,1.1)$ & .004 \\
\hline
\end{tabular}

Abbreviation: N/A, not applicable.

NOTE. $\mathrm{n}=230$ with participants who have complete information on all tested variables in both models.

Model 1: estimate of MDItotal to TMD, adjusted for age.

${ }^{\dagger}$ Model 2: estimate of individual MDI domains to TMD, adjusted for other MDI domains and age. 